\title{
A mediação familiar a partir da teoria do pluralismo jurídico comunitário-participativo em conflitos familiares indígenas
}

\author{
Family mediation from the community-participatory legal \\ pluralism theory in indigenous family conflicts
}

\author{
Silvia Ozelame Rigo Moschetta ${ }^{1}$ \\ Mylenna Roman ${ }^{2}$
}

\begin{abstract}
Resumo: O artigo busca demonstrar a aplicabilidade da mediação familiar, a partir da teoria do pluralismo jurídico comunitárioparticipativo, no âmbito dos conflitos familiares indígenas. A problemática circunscreve-se à pergunta "A mediação familiar, a partir da teoria do pluralismo jurídico comunitário-participativo, pode ser uma metodologia utilizada diante de conflitos familiares indígenas?" Tem-se como objetivo geral analisar se a mediação familiar, a partir da teoria do pluralismo jurídico comunitário-participativo, pode ser uma metodologia utilizada diante de conflitos familiares indígenas. Os objetivos específicos são verificar os fundamentos da teoria do pluralismo jurídico comunitárioparticipativo; compreender a mediação como prática interventivoparticipativa mediante os conflitos familiares; observar os conflitos familiares que se apresentam entre as famílias indígenas. A partir dessa inquietação, o método de abordagem é o dedutivo, o método de procedimento é o monográfico, a metodologia da pesquisa é exploratória, cumulada com pesquisa descritiva. Os resultados advieram do cotejo entre a mediação perante os conflitos de uma forma geral e perante os conflitos familiares indígenas. Ao fim, pode-se considerar que a mediação, como uma metodologia que prima pelo diálogo, por escuta qualificada e corresponsabilidades dos envolvidos, encontra espaço de utilização no ambiente das famílias indígenas, podendo ser manejada pelo cacique que encampa os encaminhamentos dos conflitos familiares ou em Centros Judiciários de Solução de Conflitos e Cidadania. (CEJUSC).
\end{abstract}

Palavras-chave: Pluralismo jurídico comunitário-participativo. Mediação familiar. Conflitos familiares indígenas.

\begin{abstract}
The article seeks to demonstrate the applicability of family mediation, based on the theory of community-participatory legal pluralism, in the context of indigenous family conflicts. The problem is limited to the question "Can family mediation, based on the theory of
\end{abstract}

\footnotetext{
${ }^{1}$ Doutora em Direito pela Universidade Federal de Santa Catarina - UFSC. Mestra em Direito Público e Evolução Social pela Universidade Estácio de Sá - Rio de Janeiro. Professora permanente do Programa de Mestrado Acadêmico em Direito - UNOCHAPECó na Linha de Pesquisa: Direito, Cidadania e Atores Internacionais; professora titular de Direito Civil na Graduação da UNOCHAPECÓ.

${ }^{2}$ Bolsista Edital de Pesquisa Unochapecó n. 13/REITORIA/2019. Acadêmica do $9^{\circ}$ período do curso de Direito da Unochapecó, campus Chapecó (SC).
} 
community-participatory legal pluralism, be a methodology used in the face of indigenous family conflicts?" The general objective is to analyze whether family mediation, based on the theory of community-participatory legal pluralism, can be a methodology used in the face of indigenous family conflicts. The specific objectives are to verify the foundations of the theory of community-participatory legal pluralism; understand mediation as an interventionist-participatory practice through family conflicts; observe the family conflicts that arise between indigenous families. Based on this concern, the approach method is deductive, the procedure method is monographic, the research methodology is exploratory, combined with descriptive research. The results came from the comparison between mediation in the face of conflicts in general and in the face of indigenous family conflicts. In the end, it can be considered that mediation as a methodology that strives for dialogue, for qualified listening and coresponsibility of those involved finds space for use in the environment of indigenous families, and can be handled by the chief who takes over the escalation of family conflicts or in Judicial Centers for Resolving Conflicts and Citizenship. (CEJUSC).

Palavras-chave: Community-participatory legal pluralism. Family mediation. Indigenous family conflicts.

\section{Introdução}

Como introito, ressalta-se que o artigo insta em contemplar a utilização da mediação como metodologia pautada na teoria do pluralismo jurídico comunitário-participativo - direcionada aos conflitos familiares indígenas.

A teoria do pluralismo jurídico comunitário-participativo e também os fundamentos para sua concretização - o surgimento de novos sujeitos de direito; as novas necessidades humanas fundamentais; a reordenação do espaço público; a ética da alteridade; a racionalidade emancipatória - são alicerces para uma nova consciência, uma nova ordem, desprendida da legalidade, caracterizada como inclusiva, reflexiva e justa.

De outro ponto, são absorvidos conceitos jurídicos sobre a evolução da família no ordenamento brasileiro, enriquecidos com os apontamentos que unem essa instituição na contemporaneidade; contudo, os conflitos surgidos dessa ambiência também são pautados. O conflito é congênito ao ser humano, são seus desmembramentos que exigem diferentes formas de 
buscar a almejada "solução". Em uma sociedade marcada pela cultura da sentença, não se teria outro encaminhamento senão apresentar a demanda para julgamento - a jurisdição. Inobstante o entendimento de que a segurança jurídica advém unicamente de uma decisão judicial, outros formatos de atendimento da tutela dos direitos apresentam-se, com roupagens adequadas ao encaminhamento do respectivo conflito - a mediação. Ademais, a família, por ser uma categoria coletiva, contempla desejos e interesses manifestados por seus pares; logo, por ser o conflito inerente ao ser humano, a família se vê inserida nesta teia - conflitos familiares. Como forma de prestar a tutela desses direitos, tem-se que o panorama da mediação no contexto brasileiro é promissor, e dispõe da Resolução n. 125/2010 do Conselho Nacional de Justiça; da Lei de Mediação, n. 13.140, de 2015; e do Código de Processo Civil, Lei n. 13.105, de 2015.

A especificidade reside em analisar a utilização da mediação familiar, a partir da teoria do pluralismo jurídico comunitário-participativo, dentro dos conflitos indígenas. Para abrilhantar a possibilidade concreta desse fato, compõe-se o trabalho com alternativas judiciais/extrajudiciais de encaminhamento de conflitos - no caso, indígenas.

A problemática circunscreve-se à pergunta "A mediação familiar, a partir da teoria do pluralismo jurídico comunitário-participativo, pode ser uma metodologia utilizada diante de conflitos familiares indígenas?" Tem-se como objetivo geral analisar se a mediação familiar, a partir da teoria do pluralismo jurídico comunitário-participativo, pode ser uma metodologia utilizada diante de conflitos familiares indígenas. Os objetivos específicos são verificar os fundamentos da teoria do pluralismo jurídico comunitárioparticipativo; compreender a mediação como prática interventivoparticipativa mediante os conflitos familiares; observar os conflitos familiares que se apresentam entre as famílias indígenas. A partir dessa inquietação, o método de abordagem é o dedutivo, o método de procedimento é o monográfico, a metodologia da pesquisa é exploratória, cumulada com 
pesquisa descritiva. O referencial teórico funda-se em Wolkmer (1997), Warat (2004) e Moschetta (2018).

A pesquisa não tem outra hipótese senão contemplar uma outra era, uma nova consciência que supera as dicotomias cartesianas e ascende para uma politomia marcada por um sujeito que está no centro, no caso, no umbigo das preocupações jurídicas - os indígenas -, e aceitar certa impotência ante os conflitos que se apresentam - conflitos familiares indígenas -, mas também reconhecer uma clarividência na condução de tais superações, buscando o encaminhamento mais adequado e justo - mediação familiar, mesmo diante da cultura indígena.

\section{Fundamentos da teoria do pluralismo jurídico comunitário- participativo}

O pluralismo jurídico é caracterizado pela multiplicidade de "instituições" formadoras de direito e fontes dele mesmo; pode se apresentar de formas antigas, tradicionais, conservadoras, autoritárias, modernas, progressivas, radicais ou críticas. Vale dizer, são "práticas jurídicas existentes num espaço sociopolítico, interagidas por conflitos ou consensos, podendo ser ou não oficiais e tendo sua razão de ser nas necessidades existenciais, materiais e culturais" (WOLKMER, 1997, p. 195; 2006, p. 637). Pela sua abundância de caracterizações, será tratada aqui apenas a seara de que a teoria do pluralismo jurídico é a negação de que o Estado seja a única e exclusiva fonte de todo o Direito.

Não obstante, destaca-se aqui a pontuação de Wolkmer (2013, p. 21) para pluralismo:

[...] o pluralismo engloba fenômenos espaciais e temporais com múltiplos campos de produção e aplicação, os quais compreendem, além dos aportes filosóficos, sociológicos, políticos ou culturais, uma formulação teórica e prática de pluralidade no direito. Ora, o pluralismo no direito tende a demonstrar que o poder estatal não é a única e exclusiva de todo o direito, abrindo escopo para uma 
produção e aplicação normativa centrada na força e na legitimidade de um complexo e difuso sistema de poderes, emanados dialeticamente da sociedade, de seus diversos grupos sociais, coletividades ou corpos intermediários.

Vislumbra-se que o pluralismo jurídico urge de um cenário com demandas caracterizadas e advindas de um novo modelo de reconhecimento de "instituições", quais sejam, centradas e organizadas em um complexo ímpar ao aporte estatal. Essas novas formações de pequenos "ordenamentos jurídicos" emanam suas próprias necessidades e regras, atribuindo ao Estado a competência de reconhecer os diversos meios de solução de conflitos que fazem parte da pluralidade jurídica. Nota-se tal concepção quando se observa, dentro do Direito de Família, que um determinado grupo familiar procura soluções paraestatais como alternativa para mitigar seus conflitos - contexto fortemente observado com a mediação familiar.

Agora, imerge-se nas profundezas do conceito de pluralismo jurídico comunitário-participativo. Dentre os fundamentos dessa teoria, observa-se a presença de novos sujeitos coletivos de juridicidade, reconhecendo que este sujeito "é um sujeito vivo, atuante e livre, que se autodetermina, participa e modifica a mundialidade do processo histórico-social" (WOLKMER, 1997, p. 211), cujo surgimento se dá nas "identificações valorativas e experiências vividas, buscando a satisfação das necessidades e demandas por direito" (WOLKMER, 1997, p. 215). Abrilhantado pelo conceito de Wolkmer (1997, p. 215), tem-se:

[...] são situados como identidades coletivas conscientes, mais ou menos autônomas, advindos de diversos estratos sociais, com capacidade de auto-organização e autodeterminação, interligadas por formas de vida com interesses e valores comuns, compartilhando conflitos e lutas cotidianas que expressem privações e necessidades por direitos, legitimando-se como força transformadora do poder e instituidora de uma sociedade democrática, descentralizada, participativa e igualitária.

Um destes novos sujeitos coletivos de direito se caracteriza com a família, vislumbrando que até dentro do próprio ordenamento jurídico 
destinam-se deveres como "instituição" a ela, equiparando-a ao Estado, fulcrado no comando constitucional ${ }^{3}$. Com o surgimento destes novos sujeitos, emergem necessidades humanas fundamentais, que compõem o segundo fundamento material desta teoria. Tais necessidades não se reduzem ao âmbito material, estendem-se ao cultural e existencial, que requerem novos agentes coletivos capazes de criar e instituir novos direitos, os quais ensejam necessidades humanas fundamentais, relacionadas à "falta ou privação de objetos determinados (bens materiais inerentes à produção humana em sociedade) quanto à ausência subjetiva de algo imaterial relacionado ao desejo, ações, normas, posturas modo e formas de vida, valores" (WOLKMER, 1997, p. 144).

Necessário, então, elucidar os fundamentos de ordem formal, que estão vinculadas à reordenação do espaço público, à ética da alteridade e à racionalidade emancipatória.

Contemplando o pensamento de Wolkmer (1997, p. 226), elucida-se a reordenação do espaço público como

[...] a construção de uma sociedade democrática alicerçada nas necessidades das identidades coletivas locais não só depende da participação integral de uma cidadania consciente e atuante, como ainda tem sua condição prévia nos marcos de descentralização político-administrativa e na redistribuição racional de recursos, competências e funções.

Observa-se que a reorganização do espaço público depende de meios que operacionalizem a prática de uma democracia participativa; tal mecanismo fora instituído pela CRFB/88, a qual menciona, em seu art. $1^{\circ}$, parágrafo único, que o poder do povo será exercido "por meio de representantes eleitos ou diretamente”.

\footnotetext{
${ }^{3}$ Art. 227 da CRFB/88: "É dever da família, da sociedade e do Estado assegurar à criança, ao adolescente e ao jovem, com absoluta prioridade, o direito à vida, à saúde, à alimentação, à educação, ao lazer, à profissionalização, à cultura, à dignidade, ao respeito, à liberdade e à convivência familiar e comunitária além de colocá-los a salvo de toda forma de negligência, discriminação, exploração, violência, crueldade e opressão.” (Grifo nosso).
} 
Ademais, a "prática participativa da comunidade na administração da Justiça envolve a democratização do acesso à Justiça, que tem na metodologia da mediação um exemplo" (WOLKMER, 1997, p. 230). Desta forma, resta clarividente que a mediação familiar compõe uma das maneiras de operacionalizar a democracia participativa dentro da sociedade, tendo em vista que ela é acionada para a solução de um conflito dentro de determinado grupo familiar, para que, a partir de suas próprias compreensões e decisões, seja construída a intervenção necessária, dentro da ambiguidade trazida pelas partes.

Ainda, observa-se a teoria de Wolkmer (1997, p. 233, grifo nosso) a refletir que

[...] o que importa ter presente na reordenação política do espaço público, com o consequente processo de democracia descentralizada e participativa, é descortinar uma sociedade pluralista marcada pela convivência dos conflitos e das diferenças, propiciando uma outra legitimidade embasada nas necessidades fundamentais de sujeitos coletivos insurgentes, que, com suas práticas, relações e reivindicações cotidianas, passam a ser encarados como fontes de produção jurídica não-estatais.

A ética de alteridade emerge das necessidades humanas entre aqueles que se encontram marginalizados ${ }^{4}$, traz consigo uma nova ordem de valores éticos e também "parte de uma pluralidade de formas de vida, traduz a singularidade de certos valores específicos [...], representados basicamente pela emancipação, autonomia individual e coletiva, solidariedade, justiça e satisfação das necessidades humanas” (WOLKMER, 1997. p. 241).

Para tanto, busca-se tal compreensão com o conceito de Wolkmer (1997. p. 244, grifo nosso), de que se devem

[...] reconhecer na contextualização periférica da cultura capitalista latino-americana e brasileira as possibilidades de uma nova ética de teor pedagógico e libertário, gerada no bojo das relações conflituosas e de práticas cotidianas configuradas, quer por sujeitos

\footnotetext{
${ }^{4}$ A ética da alteridade tem por objetivo gerar uma "prática pedagógica libertadora" que seja capaz de emancipar os "sujeitos históricos" que estão oprimidos, injustiçados e excluídos (WOLKMER, 1997, p. 241).
} 
coletivos, indistintamente, que especificamente pelos novos movimentos sociais.

Como terceiro e último fundamento teórico, há a racionalidade emancipatória, a qual reflete interesses, carências e necessidades vitais, comprometidas com a emancipação e autonomia da essência humana ${ }^{5}$ (WOLKMER, 1997, p. 244), as quais ensejam um novo modelo de contexto jurisdicional, que visa superar os métodos formalmente enraizados dentro do Direito.

Finda-se, então, por absorver que o pluralismo jurídico comunitárioparticipativo preconiza um novo "agir jurídico" diante do engendramento de um novo sujeito de direito, que busca, única e exclusivamente, mitigar suas necessidades jurídicas, com mecanismos aptos dentro de sua própria realidade; neste caso, aqui abordados apenas na seara do Direito de Família, sobretudo diante dos conflitos familiares.

\section{Mediação familiar como prática interventivo-participativa}

São relevantes alguns aspectos da colonização portuguesa que deixaram resquícios no Direito de Família. Para tanto, justifica-se a proposta trazida por Casa-Grande e Senzala obra de Freyre (2006) que traz à tona o encontro da cultura portuguesa, africana e indígena em um território delimitado: o Brasil. Naquele século, a miscigenação do branco com o de cor criou uma nova relação entre culturas: o imigrante tornou-se fundador de uma nova ordem econômica e social, mitigando a casa-grande, e a senzala organizou-se em um sistema composto por todas as relações, ou seja, relações sociais, econômicas, políticas, sexuais, higiênicas, produtoras, de transporte, de vida e de família. Esta família, basilarmente patriarcal,

${ }^{5}$ Formando uma racionalidade evoluída que implica a concepção de um novo contexto judicial, destinado a vencer a desgostosa composição "rígida" do ordenamento jurídico eminentemente formalista. Tendo em vista que novos problemas nunca serão solucionados por velhos métodos, que implicam única e exclusivamente a aplicação do Direito de Família já ultrapassado. 
tinha como alojamento "uma sociedade agrária na estrutura, escravocrata na técnica de exploração econômica, híbrida de índio - e mais tarde de negro - na composição" (FREYRE, 2006).

Entretanto, não se pode negar que, dentro da evolução familista, circunscrevem ao longo dos anos essas relações o sentimento e a afetividade, conforme conceituado por Pontes de Miranda (1917, p. 171):

\footnotetext{
Do par conjugal à família, do clã à fratria, à tribo, à nação, às chamadas raças, aos continentes, às civilizações, há a mesma exaltação sentimental, fecunda, que amplifica o eu, aumenta, cerebralmente todos os valores, transforma o objeto amado em sinal de sinais, alusão simbólica a tudo que é belo. É assim que se explicam as paixões do grupo binário (homem, mulher).
}

O reconhecimento atual de família - após o passar de leis e códigos funda-se em premissas fraternais e de reciprocidade, com vistas singulares e afáveis. Este "reconhecimento" foi concebido após uma longa evolução e despetrificação de conceitos de ordem jurídica, moral, religiosa, política, social e filosófica, que vão muito além da normatividade existente. A família, instituída desde 88 como "base da sociedade, tem especial proteção do Estado", tem sua manifestação de diversas formas estatais, contudo vislumbra-se, em consonância com a teoria do pluralismo jurídico comunitário-participativo, que o Ente não é o único provedor de fontes de direito.

Neste ínterim, verifica-se que, com o pluralismo jurídico, há diversos outros meios para solução de conflitos que são gerados dentro da “instituição" da família. Nota-se que o art. $3^{\circ}, \S 2^{\circ}$ da Lei 13.105 , de 2015 Código de Processo Civil (BRASIL, 2015a) - alvitra que "O Estado promoverá, sempre que possível, a solução consensual dos conflitos"; estes, instituídos, são caracterizados com a mediação, a conciliação e a arbitragem.

Em 29 de novembro de 2010, foi publicada a Resolução 125 do CNJ (BRASIL, 2010), que dispõe sobre a Política Judiciária Nacional de Tratamento Adequado dos Conflitos de Interesses no âmbito do Poder 
Judiciário, entre outras providências. Essa resolução tem apontamentos acerca do acesso à justiça, da cultura da pacificação e dos métodos alternativos de resolução de conflitos, orientando os parâmetros acerca da aplicação da mediação e da conciliação. Como exemplo das diretrizes e concepções estruturais que a referida resolução trouxe, tem-se a adoção da semana da conciliação realizada pelo Poder Judiciário, bem como a instalação de Centros Judiciários de Solução de Conflitos e Cidadania CEJUSC, os quais concentrarão a realização das sessões de conciliação e mediação que estejam a cargo de conciliador e mediador dos órgãos por eles abrangidos, ou seja, são oferecidos outros mecanismos de soluções de controvérsias - meios consensuais, como a mediação. ${ }^{6}$

Para tanto, a mediação instituída pela Lei 13.140/15 fora brilhantemente apontada por Barbosa (2015, p. 34, grifo nosso):

\begin{abstract}
Mediação é a linguagem do terceiro milênio, e a eficácia de seu emprego resulta em construção de passarelas entre pessoas e grupos, derrubando qualquer muro, que ainda exista, inclusive simbólico, a exemplo do preconceito. Quando a comunicação acontece, há uma transformação do conflito, positivamente, pois suas potencialidades transformam-se em força motriz para a renovação. Trata-se do alcance da liberdade perdida.
\end{abstract}

Por meio da Emenda Regimental n. 23, de 28 de setembro de 2016, o Superior Tribunal de Justiça (STJ) (BRASIL, 2016) dispõe e modifica dispositivos do Regimento Interno para disciplinar o procedimento de mediação, com a indicação de Ministro pelo Presidente para coordenar o Centro de Soluções Consensuais de Conflitos do STJ, cuja atribuição será a

\footnotetext{
${ }^{6}$ Resolução 125 do CNJ, que, no parágrafo único do art. $1^{\circ}$, devidamente atualizado, assim dispõe: "Aos órgãos judiciários incumbe, nos termos do art. 334 do Novo Código de Processo Civil combinado com o art. 27 da Lei de Mediação, antes da solução adjudicada mediante sentença, oferecer outros mecanismos de soluções de controvérsias, em especial os chamados meios consensuais, como a mediação e a conciliação, bem assim prestar atendimento e orientação ao cidadão." (BRASIL, 2010).
} 


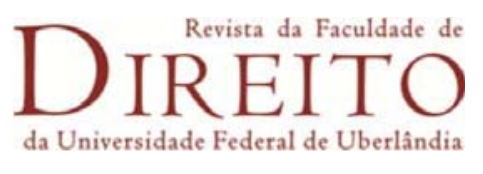

realização de sessões de conciliação e mediação, com a designação de mediador judicial. ${ }^{7}$

O Direito de Família pétreo e anteriormente imutado abarrotava o judiciário com técnicas para resolução de seus conflitos. Assim, "a realidade dos conflitos familiares contém um indistinto emaranhado de conflitos legais e emocionais, e quando não são resolvidos pelos protagonistas, transformamse em disputas intermináveis nas mãos de terceiros [...]" (SERPA, 1999, p. 17).

A mediação apresentada por Warat $(1996,2004)$ não é outra senão a pautada na alteridade: estar atento para o outro no âmbito dos relacionamentos, buscar o melhor de si para então imbricar o outro numa comunhão de interesses. O ofício do mediador surge quando há necessidade de um terceiro que auxilie no ajuste desses interesses, que a autocomposição seja a partir das tensões dos mediandos para se oportunizar a escuta e transformar o conflito, seguindo para a compreensão das responsabilidades e, consequentemente, dos direitos e deveres.

Nessa perspectiva, a reflexão aponta para o status da mediação, ou seja, estar mediado é estar harmonizado, equilibrado, é a tentativa de viver no presente, porquanto é preciso sacrificar o futuro pelo presente, mas nunca sacrificar o presente pelo futuro. Por isso que o ofício do mediador é mais complexo do que aparenta; é um trabalho de sentir, compreender e transmitir sentimentos capazes de refletir um entendimento acerca das posições diferentes das partes. É mostrar que o conflito não tem apenas o cunho negativo, pelo contrário, ele é inerente às relações humanas e serve

\footnotetext{
${ }^{7}$ Superior Tribuna de Justiça. Emenda Regimental n ${ }^{\circ} 23$, de 28 de setembro de 2016. Art. 288-A. "O Centro de Soluções Consensuais de Conflitos do Superior Tribunal de Justiça, responsável por realizar sessões e audiências de conciliação e mediação e por desenvolver programas destinados a auxiliar, orientar e estimular a autocomposição, será coordenado pelo Ministro designado pelo Presidente. Art. 288-B. O mediador judicial será designado pelo Ministro Coordenador dentre aqueles que constarem do cadastro de mediadores mantido pelo Centro de Soluções Consensuais de Conflitos do Superior Tribunal de Justiça ou de cadastro de âmbito nacional. $\S 1^{\circ} \mathrm{O}$ relator poderá solicitar ao Centro a indicação de mediador para auxiliá-lo também em procedimento de conciliação. $\S 2^{\circ} \mathrm{O}$ relator pode encaminhar o processo de ofício para a mediação."
} 
como forma construtiva dos indivíduos. O modelo de mediação não é uma metodologia que prima tão somente pelo acordo; trata-se de um modelo de mediação hedonista, que busca uma transformação entre as partes e o conflito que lhes assola. Não apenas uma forma de fazer cessar um problema, mas a ressignificação da autonomia que ficou adormecida pelos embalos da Modernidade (WARAT, 2004, p. 25, 31-32).

A mediação aplicada ao Direito de Família traz em cada conflito um enorme envolvimento emocional e afetivo, que não pode se tornar competitivo e chantagista - risco que se corre quando não se é dado tratamento isonômico e autônomo às partes. Esta prática tem seus princípios elencados na Lei 13.140/15 (BRASIL, 2015b), onde encontram-se "[...] imparcialidade do mediador; isonomia entre as partes; oralidade; informalidade; autonomia da vontade das partes; busca do consenso; confidencialidade; e, boa-fé."8

O uso da mediação incentiva a autonomia individual, a interação entre os envolvidos por meio da escuta qualificada e da comunicação, fazendo com que haja harmonia e respeito na relação, reduzindo as tensões e operando na transformação do contexto conflituoso, com possibilidades de restabelecimento da relacionalidade; por isso o mediador procura restabelecer a comunicação produtiva entre os mediandos, com o fim de tornar o diálogo possível e de construir uma relação pautada na colaboração.

A mediação familiar permite que os interessados/mediandos tenham autonomia e capacidade para gerir e solucionar o conflito existente, em face dos procedimentos utilizados na condução da sessão de mediação. Esta deve ser um processo dinâmico e flexível, em que fatores sociais, econômicos e culturais das pessoas sejam levados em consideração para a escolha do modo de abordagem do mediador (terceiro), a fim de se estabelecer a comunicação e alcançar a relação de equilíbrio entre as forças em disputa.

\footnotetext{
${ }^{8}$ Lei n. $13.140 / 2015$, art. $2^{\circ}$.
} 


\section{A mediação familiar a partir da teoria do pluralismo jurídico comunitário-participativo no contexto dos conflitos familiares indígenas}

De acordo com Censo Demográfico realizado pelo IBGE (2010), a população indígena brasileira é de 817.963 indígenas. Os indígenas se organizam de maneira coletiva e constituem aldeias, sendo que, como organização familiar, "um ou mais filhos casados vivem com seus cônjuges na casa dos pais, dando então ao grupo familiar a conformação de uma família extensa, ou seja, uma rede familiar ligando consanguíneos, aliados e descendentes ao longo de ao menos três gerações". Dentro dessa organização, o poder fica centralizado com o chefe da família: "(geralmente, o ascendente vivo mais respeitado) detém a autoridade política e o comando das atividades econômicas", possuindo atribuição também para organizar a família extensa a fim de realizarem os trabalhos pesados e leves conjuntamente (plantio, colheita, caçada, cuidado com as crianças) (LABURTHE-TOLRA; WARNIER, 1997, p. 107).

Sobre o reconhecimento da cultura indígena no Brasil, o Decreto n. 5.051/2004, que promulgou a Convenção n. 169 da Organização Internacional do Trabalho (OIT), sobre povos indígenas e tribais, traz em seu art. $8^{\circ}$, item 2 :

2. Esses povos deverão ter o direito de conservar seus costumes e instituições próprias, desde que eles não sejam incompatíveis com os direitos fundamentais definidos pelo sistema jurídico nacional nem com os direitos humanos internacionalmente reconhecidos. Sempre que for necessário, deverão ser estabelecidos procedimentos para se solucionar os conflitos que possam surgir na aplicação deste princípio. (Grifo nosso).

Neste contexto, observa-se a descrição de como os conflitos se encontram disseminados no corpo social, originados de divergências entre os envolvidos, entre eles e as entidades, entre estas propriamente ditas. Por 
conta de um momento de incertezas de ordem econômica, social, jurídica, política, filosófica e emocional, eles também ocorrem nos ambientes familiares indígenas e, como sugestão, apresenta-se a teoria do pluralismo jurídico comunitário-participativo cumulada com a teoria pós-moderna do Direito de Família (MOSCHETTA, 2018), que tem a mediação como prática interventivo-participativa na dimensão do pluralismo jurídico, para buscar soluções na garantia de direitos fundamentais das famílias indígenas envoltas em conflitos familiares.

Inobstante a constituição da Família, a tutela jurídica necessária para os conflitos familiares advém do paradigma do pluralismo jurídico comunitário-participativo, sobretudo a mediação, como forma de fortalecer o respeito ao espaço coletivo familiar. A teoria pós-moderna do Direito de Família tem como sujeito coletivo de direito a família; entre as necessidades humanas fundamentais, a afetividade; e a mediação como meio alternativo de intervenção nos conflitos familiares, a qual possui no instituto da mediação, previsto pelas legislações e resolução mencionada alhures, uma proposta de encaminhamento dos conflitos familiares.

A tabela a seguir, aproxima as duas teorias nas categorias que são compatíveis a oferecer uma nova forma de encaminhar os conflitos, partindo do entendimento da família como sujeito coletivo em busca de uma fisionomia plural, reflexiva, prospectiva, discursiva e relativa por estar contemplada como um bem extrapatrimonial.

Tabela 1: Possibilidades de encaminhamento de Conflitos

\begin{tabular}{|l|l|}
\hline $\begin{array}{c}\text { Fundamentos da teoria do pluralismo } \\
\text { jurídico comunitário-participativo }\end{array}$ & $\begin{array}{l}\text { Fundamentos da teoria pós-moderna do } \\
\text { direito de família }\end{array}$ \\
\hline $1-$ Novos sujeitos coletivos de juridicidade & $1-$ Família como sujeito coletivo de direito \\
\hline 2 - Necessidades humanas fundamentais & $\begin{array}{l}2-\text { Necessidades humanas fundamentais de } \\
\text { cunho imaterial: afetividade }\end{array}$ \\
\hline $\begin{array}{l}3-\text { Reordenação do espaço público, } \\
\text { contempla prática participativa da da }\end{array}$ & $\begin{array}{l}3 \text { - Democratização do acesso à Justiça: } \\
\text { mediação familiar judicial e extrajudicial }\end{array}$ \\
\hline
\end{tabular}


Fonte: Wolkmer (1997) e Moschetta (2018).

A família, e aqui, em especial, a indígena, caracteriza-se como um novo "sujeito coletivo de direito" - abarcado pela teoria do pluralismo jurídico comunitário-participativo -, possuindo conflitos que, via de regra, são geridos dentro da própria organização. Evidencia-se, pois, o conceito saindo do teórico e tornando-se prático, palpável e aplicável, visando que esse novo "sujeito" emerge em novas necessidades (materiais, culturais e existenciais), e o Estado - comumente - não é parte presente na resolução delas.

A mediação se traduz como uma prática participativa, com método e metodologia próprios, além de regramento procedimental, caso necessário, que prima pela participação equânime dos envolvidos no conflito e, consequentemente, propicia sua emancipação para que possam (res)significar os conflitos atuais e vindouros.

Aqui, então, a insistência se dá em como a aplicabilidade da mediação seria eficaz para a solução dos conflitos familiares indígenas, considerando ser uma prática judicial ou extrajudicial, e vislumbrando que os indígenas resolveriam suas eventuais demandas com a construção mútua de uma solução palpável para a sua realidade.

No Brasil, há manifestações ainda muito tímidas de aplicação da mediação estritamente limitada aos indígenas. Contudo, cresce de maneira audaz a concretização dessa teoria. Em 2015, o "ministro Ricardo Lewandowski inaugurou [...] o primeiro polo de conciliação indígena de um Centro Judiciário de Solução de Conflitos e Cidadania (CEJUSC) no País, localizado na Comunidade Maturuca, dentro da reserva indígena Raposa 
Serra do Sol, em Roraima". ${ }^{9}$ Ademais, "para o lançamento desse polo, 16 índios foram treinados e poderão atuar nas mediações de conflitos que surjam dentro da própria reserva, com o intuito de resolver os casos antes que cheguem aos tribunais" (ABIORANA, 2019). Atualmente, este é o único centro de conciliação exclusivamente para solução de conflitos indígenas.

Observa-se que existem iniciativas para inauguração de novos polos:

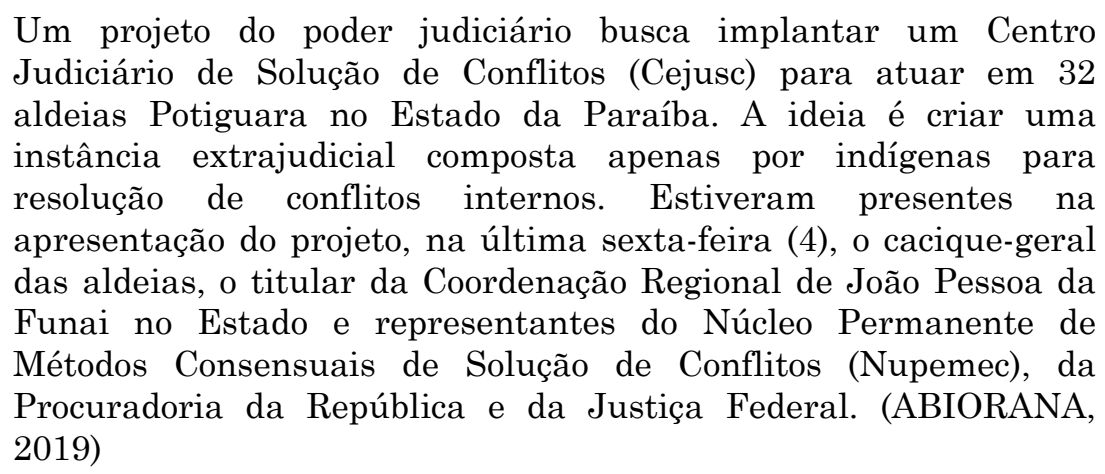

Os conflitos nunca desaparecem, eles "se transformam" porque se tenta intervir sobre eles e não sobre o sentimento das pessoas, por isso "é recomendável, na presença de um conflito pessoal, intervir sobre si mesmo, transformar-se internamente, então o conflito se dissolverá (se todas as partes comprometidas fizerem a mesma coisa)" (WARAT, 2004, p. 27).

A implementação de centros de resolução de conflitos torna palpável a teoria do pluralismo jurídico comunitário-participativo dentro das demandas indígenas, onde se comprova a aplicabilidade de um método não extrajudicial dentro da "instituição" que formou um novo ordenamento jurídico, em que novos sujeitos de direito possuem novas demandas e novos métodos para a solução destas. Sob a perspectiva extrajudicial, tem-se que o papel de mediador na aldeia indígena, mediação extrajudicial, é exercido pelo cacique, o qual possui a incumbência de aproximar os indígenas envolvidos no conflito e promover o diálogo com os ajustes necessários à

\footnotetext{
9 “'É um avanço muito importante para o Judiciário brasileiro', disse o ministro, ressaltando o caráter inédito dessa iniciativa. Segundo Lewandowski, o Poder Judiciário 'está convencido de que deve assegurar os direitos indígenas sem quaisquer restrições'."
} 
casuística apresentada.

\section{Considerações Finais}

A teoria do pluralismo jurídico, sobretudo o comunitário-participativo propicia a comunhão de aportes filosóficos, sociológicos, políticos ou culturais configurando a pluralidade no direito que se espraia em poderes cujo destino são grupos sociais e coletividade, e diante do recorte científico aqui proposto, essa multiplicidade alberga as famílias indígenas. É cediço que os conflitos são inerentes ao ser humano em todas suas relações, porém o conflito na ambiência familiar pode ser entendido como a divergência surgida na interação entre pessoas ou grupos sobre interesses, necessidades ou pontos de vista percebidos como incompatíveis, pois ele é uma relação, é um processo que se constrói com a coparticipação e corresponsabilidade dos envolvidos, o que remete ao fato de que, na sua construção, todos os envolvidos contribuem, seja nas dimensões das ações, das emoções e das percepções.

A mediação waratiana fulcra-se na atenção aos relacionamentos, em buscar o melhor de si para haver comunhão de interesses entre os envolvidos, isso se traduz em transmutar tensões, rancores dos mediandos para que cada um compreenda suas corresponsabilidades e se formalize direitos e deveres.

A teoria pós-moderna do direito de família bebericou na fonte da teoria do pluralismo jurídico comunitário-participativo e trouxe para o cenário do direito familista os fundamentos necessários para categorizar família como um sujeito coletivo de direito; pautada em necessidades humanas de ordem imaterial como a afetividade; e oferecer o acesso à Justiça pela via da mediação familiar, quer seja judicial ou extrajudicial. A mediação judicial seria pelo viés do CEJUSC - Centro Judiciário de Solução de Conflitos e Cidadania, vale dizer, polos de mediações de conflitos dentro da própria 
reserva, com o intuito de resolver os casos antes de aportarem nos tribunais, sobretudo os conflitos familiares. A mediação extrajudicial se perfectibilizaria na atuação do mediador - o cacique e suas atribuições na aldeia, que no caso da mediação comtemplaria o ofício do mediador que é a organização do diálogo, da escuta, dos interesses envolvidos para que possam encaminhar o conflito a partir da compreensão e realidade dos próprios mediandos, primando pela ressignificação da autonomia, no caso os indígenas.

\section{Referências}

ABIORANA, Kézia. Judiciário estuda implantar unidade Potiguara de solução de conflitos. $2019 . \quad$ Disponível em: $<$ http://www.funai.gov.br/index.php/comunicacao/noticias/5684-judiciario-estuda-implantarunidade-potiguara-de-solucao-de-conflitos>. Acesso em: 7 ago. 2020.

BARBOSA, Águida Arruda. Mediação Familiar Interdisciplinar. São Paulo: Atlas, 2015.

BRASIL. Constituição da República Federativa do Brasil de 1988. Brasília, 1988. Disponível em: <http://www.planalto.gov.br/ccivil_03/constituicao/constituicao.htm>. Acesso em: 5 ago. 2020.

Conselho Nacional de Justiça. Resolução n. 125, de 29 de novembro de 2010. Brasília, 2010c. Disponível em: <http://s.conjur.com.br/dl/resolucao-1252010-conselhonacional.pdf>. Acesso em: 23 out. 2020.

Código de Processo Civil. Brasília, 2015a. Disponível em: $<$ http://www.planalto.gov.br/ccivil_03/_ato2015-2018/2015/lei/113105.htm>. Acesso em: 6 ago. 2020.

Lei $n^{\circ}$ 13.140, de 26 de junho de 2015. Dispõe sobre a mediação entre particulares como meio de solução de controvérsias e sobre a autocomposição de conflitos no âmbito da administração pública; altera a Lei $\mathrm{n}^{\circ}$ 9.469, de 10 de julho de 1997, e o Decreto $\mathrm{n}^{0} 70.235$, de 6 de março de 1972; e revoga o $\S 2^{\circ}$ do art. $6^{\circ}$ da Lei ${ }^{\circ} 9.469$, de 10 de julho de 1997. Brasília, 2015b. Disponível em: <http://www.planalto.gov.br/ccivil_03/_ato20152018/2015/lei/l13140.htm>. Acesso em: 6 ago. 2020.

Emenda Regimental $n^{\circ} 23$, de 28 de setembro de 2016. Dispõe sobre alteração do art. 288 do Regimento Interno do Superior Tribunal de Justiça e outras disposições. Disponível em: https://www.stj.jus.br/publicacaoinstitucional/index.php/Regimento/article/view/3117/4021> . Acesso em 10 fev. 2021.

social básica. Brasília, $2017 . \quad$ Disponível proteção $<$ http://www.mds.gov.br/webarquivos/publicacao/assistencia_social/cartilhas/OrientacoesTec nicas_TrabalhoSocialcomFamiliasIndigenas.pdf>. Acesso em: 6 ago. 2020.

Decreto $\mathbf{n}^{\circ}$ 5.051, de 19 de abril de 2004. Promulga a Convenção $n^{0} 169$ da Organização Internacional do Trabalho. OIT sobre povos indígenas e tribais. Disponível em: $<$ http://www.mpf.mp.br/atuacao-tematica/ccr6/documentos-epublicacoes/legislacao/legislacao-docs/convencoes-internacionais/convecao169.pdf/view>. Acesso em: 2 mar. 2021. 
FREYRE, Gilberto. Casa Grande \& Senzala: formação da família brasileira sob o regime da economia patriarcal. 51. ed. São Paulo: Global, 2006.

IBGE - INSTITUTO BRASILEIRO DE GEOGRAFIA E ESTATÍSTICA. Indígenas. 2010. Disponível em: <https://indigenas.ibge.gov.br/graficos-e-tabelas-2.html>. Acesso em: 15 mar. 2021.

LABURTHE-TOLRA, P.; WARNIER, J. P. O Parentesco. Etnologia - Antropologia. Petrópolis: Vozes, 1997.

MINISTRO Lewandowski inaugura polo de conciliação indígena inédito no país. Disponível em: <http://www.stf.jus.br/portal/cms/verNoticiaDetalhe.asp?idConteudo=299145>. Acesso em: 7 ago. 2020.

MOSCHETTA, Sílvia Ozelame Rigo. Teoria Pós-Moderna do Direito de Família: a mediação como prática interventivo-participativa na dimensão do pluralismo jurídico. Rio de Janeiro: Lumen Juris, 2018.

PONTES DE MIRANDA, Francisco Cavalcanti. Direito de família. Rio de Janeiro: Jacinto Ribeiro dos Santos, 1917.

SERPA, Maria de Nazareth. Mediação de família. Belo Horizonte: Del Rey, 1999.

WARAT, Luis Alberto. Por quien cantan las sirenas: informe sobre eco-cidadania, género y derecho - incidências del barroco en el pensamiento jurídico. Joaçaba/Florianópolis: UNOESC/CPGD-UFSC, 1996.

2004. $423 \mathrm{p}$

Surfando na pororoca: o ofício do mediador. Florianópolis: Fundação Boiteux,

WOLKMER, Antônio Carlos. Pluralismo jurídico: fundamentos de uma nova cultura no direito. 2. ed. São Paulo: Alfa Omega, 1997.

Pluralismo jurídico. In: BARRETO, Vicente de Paulo (Coord.). Dicionário de

filosofia do direito. São Leopoldo: Unisinos; Rio de Janeiro: Renovar, 2006. 874 p.

.MELO, Milena Petters. Constitucionalismo latino-americano: tendências contemporâneas. Curitiba: Juruá, 2013.

Artigo recebido em: 29/03/2021.

Aceito para publicação em: 19/05/2021. 